Gut, 1987, 28, S1, 203-205

\title{
Tryptophan rich diet as a new approach to study the serotoninergic enteropancreatic axis
}

\author{
B GÖKE, G RICHTER, A GREBE, V KEIM, AND R ARNOLD \\ From the Departments of Internal Medicine and Physiology, Philipps University of Marburg, Marburg, \\ Federal Republic of Germany
}

SUMMARY The influence of a tryptophan enriched diet (L-tryptophan added as $1 \%$ of total diet), fed over 10 days, on the rat duodenum and pancreas was studied by immunohistology, measurements of serotonin and tryptophan tissue concentrations by HPLC, and incubations of pancreatic lobules. Ingestion of a tryptophan enriched diet resulted in increased contents of tryptophan and serotonin in the duodenum that was not accompanied by a significant change of the serotonin cell density. Neither basal nor CCK-stimulated amylase release from isolated pancreatic lobules was altered after tryptophan enriched food. Although serotonin could be extracted from the pancreas, no increase in serotonin concentration was detected after ingestion of the tryptophan diet. A 'serotonin loading' diet may be a useful tool to study the significance of amines produced by gut endocrine cells in respect to enteropancreatic connections.

The exocrine pancreas possesses the ability to regulate rates of synthesis of various digestive enzymes to meet the demands of diet composition. There is evidence, that certain dietary components entering the gut lumen induce a release of gastrointestinal hormones, which in turn alter the pattern of pancreatic enzyme synthesis. ${ }^{12}$

Serotonin is considered to be involved in intracellular control mechanisms of peptide and protein secreting cells. ${ }^{34}$ It is synthesised from dietary tryptophan, mainly by enterochromaffin cells in the upper small intestine. ${ }^{5}$ Serotonin and related biogenic amines occur in many cells known or believed to secrete polypeptide hormones. ${ }^{356}$ Several possibilities, therefore, exist for a role for this biogenic amine in the regulation of protein synthesis and secretion of the pancreas. We studied whether a tryptophan enriched diet influences the numerical density of duodenal serotonin cells and/or the concentrations of serotonin in the rat duodenum and pancreas. Furthermore, it was evaluated whether the amylase release from isolated pancreatic lobules is influenced by ingestion of a tryptophan enriched diet.

Address for correspondence: Dr B Göke, Dept of Internal Medicine, Philipps University of Marburg, Baldinger Strasse, 3550, Marburg, FRG.

\section{Methods}

ANIMALS

Female Wistar rats $(180-200 \mathrm{~g})$ were pair fed a standard (Altromin 1324; Altromin, Lage/Lippe, FRG) or tryptophan enriched (L-tryptophan added as $1 \%$ of total diet) food over 10 days. Thereafter, the animals were fasted over $24 \mathrm{~h}$ and killed under ether anaesthesia. The pancreas was removed and pancreatic lobules were prepared ${ }^{7}$ in Krebs-RingerHEPES buffer. After equilibration for 30 minutes the amylase release from the lobules was stimulated by addition of caerulein $(1,0.1,0.01,0.001 \mu \mathrm{M})$ to the incubation buffer over $30 \mathrm{~min}$ or was left unstimulated to study basal enzyme release. In six animals out of each group (tryptophan-fed or controls) the pancreatic serotonin concentration was measured. Tissue samples of the duodenum were saved for both immunohistology and extraction of tryptophan and serotonin. For immunohistology, tissue specimens were stained for serotonin using the PAP-technique as described elsewhere ${ }^{8}$ using an antibody (dilution 1: 8000) raised in rabbits (IBL, Hamburg, FRG). Serotonin cells were counted in at least 10 adjacent fields of $316 \mu \mathrm{m}$ length $\times$ total mucosal height. Average mucosal height was calculated using the 


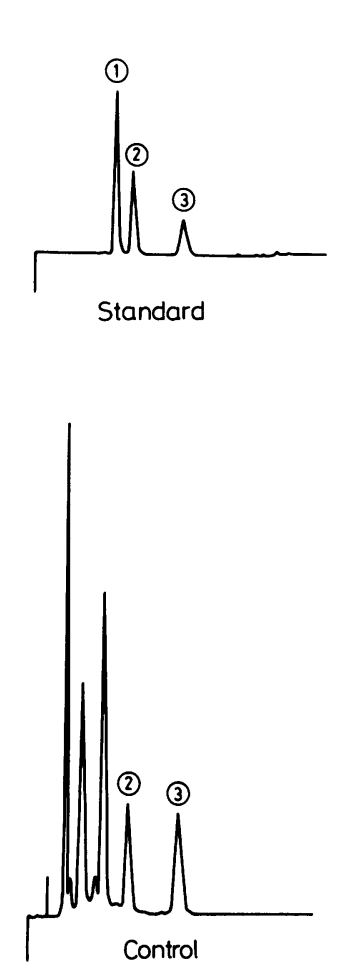

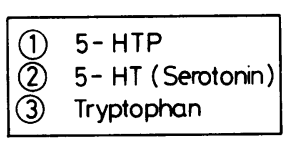

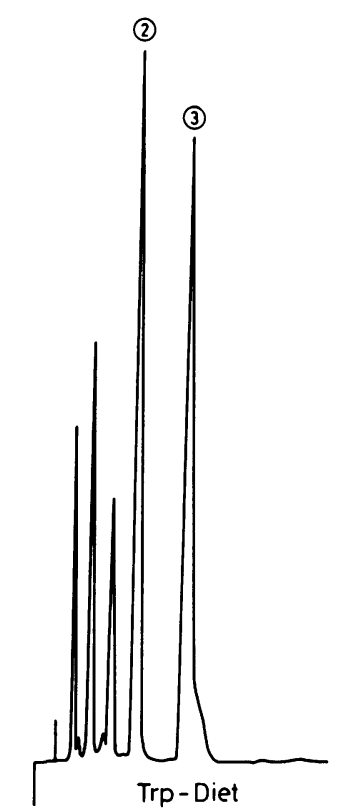

Figure Influence of a tryptophan rich diet on the tryptophan and serotonin content of the rat duodenum. Representative HPLC chromatograms of a standard analysis and of material of duodenal tissue obtained from control or tryptophan fed animals are shown.

semiautomatic morphometric system Morphomat 30 (Zeiss, Oberkochen, FRG). Extraction procedures were performed by homogenisation of the frozen tissue in $0.4 \mathrm{M}$ perchloric acid containing EDTA $(5 \mathrm{~g} / \mathrm{l})$ and ascorbic acid $(10 \mathrm{~g} / \mathrm{l})$. Serotonin and tryptophan concentrations in an aliquot $(50 \mu \mathrm{l})$ of tissue extract were measured by reverse-phase HPLC using a Waters Radial PAK $\mu$ Bondapak C 18 cartridge and a Kontron SFM-23 fluorimeter. ${ }^{9}$

\section{Results}

Representative chromatographic profiles of a standard injection and of aliquots of duodenal extracts from tryptophan-fed and control animals are shown in the Fig. The minimum detectable serotonin concentration was $0.5 \mathrm{ng} / \mathrm{ml}$. Recovery of serotonin $(50 \mathrm{ng})$ subjected to the extraction and chromatography procedure was $85 \%$. Ingestion of tryptophan enriched diet resulted in increased concentrations of serotonin and tryptophan in the duodenum (Table 1). Although serotonin could be extracted from the

Table 1 Tryptophan and serotonin concentrations in the rat duodenum and pancreas after tryptophan (Trp)-rich diet.

\begin{tabular}{lcc}
\hline Duodenum & Tryptophan & Serotonin \\
L-Trp diet & $4113 \pm 1220^{*}$ & $10375 \pm 8585 \dagger$ \\
controls & $1866 \pm 965$ & $3659 \pm 1553$ \\
Pancreas & Serotonin & \\
L-Trp diet & $547 \pm 248$ & \\
controls & $525 \pm 210$ & \\
\hline
\end{tabular}

Means $\pm S D ; n g / g$ wet weight $n=6$ each group $p<0.01^{*}$; $\mathrm{p}<0.05+$; (U-test; Wilcoxon, Mann and Whitney).

Table 2 Morphometric analysis of serotonin cells and mucosal height in the rat duodenum after tryptophan (TRP)-rich diet.

\begin{tabular}{lll}
\hline & Mucosal height $(\mu \mathrm{m})$ & $\begin{array}{l}\text { Numerical density of } \\
\text { serotonin cells }(\text { cells } / \mathrm{mm})\end{array}$ \\
\hline $\begin{array}{l}\text { L-Trp diet } \\
\text { controls }\end{array}$ & $561 \pm 103(13)$ & $22 \cdot 7 \pm 15 \cdot 8(13)$ \\
& $585 \pm 93(15)$ & $16 \cdot 6 \pm 7 \cdot 3(15)$ \\
\hline
\end{tabular}

Means $\pm \mathrm{DS} ; \mathrm{n}$ in parenthesis.

pancreas, no increase was detected after the tryptophan enriched diet (Table 1). The effects of feeding tryptophan on serotonin concentration in the duodenum were not accompanied by significant changes of serotonin cell density or mucosal height (Table 2). Neither basal nor CCK-stimulated amylase release from isolated lobules was affected after feeding of tryptophan-enriched food (data not shown).

\section{Discussion}

Certain gut endocrine cells contain physiologically important biogenic monoamines like serotonin. They are referred to as enterochromaffin cells. ${ }^{3-5}$

Immunohistochemical identification of EC-cells has been successfully performed with the use of serotonin antisera. ${ }^{1011}$ We were able to identify serotonin containing cells in the rat duodenum but failed to show in preliminary experiments corresponding cells in the pancreas. On the other hand, serotonin could be extracted from the pancreas. Lower concentrations of serotonin as an antigen in pancreatic tissue compared with those in the duodenum may account for the failure to detect serotonin containing cells by our immunohistological procedure. An increase of serotonin concentrations by feeding tryptophan could not be found. This is in accordance with a previous study in mice, which showed that the pancreas did not utilise tryptophan as a precursor of serotonin but rapidly converted 5-hydroxytryptophan into serotonin. ${ }^{12}$ The reason for this might be a lack of hydroxylating enzymes converting tryptophan to 
the serotonin precursor 5-hydroxytryptophan in the pancreas. $^{3}$

Ingestion of tryptophan enriched diet resulted in increased concentrations of serotonin and tryptophan, measured by HPLC, in the duodenum. These increases were not accompanied with significant changes in the numerical area density of the serotonin cells. It seems reasonable to assume that the elevation of serotonin concentrations is caused by an accumulation in a limited number of inducible cells. An evaluation of volume density of serotonin containing cells should offer a better opportunity to support this assumption. We conclude that administration of tryptophan enriched food induces a 'serotonin loading' of the gut but not the pancreas without altering the serotonin cell density in the duodenum.

Dr Göke was supported by DFG-Grant Go 417/1-1.

\section{References}

1 Solomon TE. Regulation of exocrine pancreatic cell proliferation and enzyme synthesis. In: Johnson LR, ed. Physiology of the gastrointestinal tract. New York: Raven Press, 1981: 873-92.

2 Göke B, Printz H, Koop I, et al. Endogenous CCKrelease and pancreatic growth in rats after feeding a proteinase inhibitor (camostate). Pancreas 1986; 1: 509-15.

3 Larsson LI. Gastrointestinal cells producing endocrine, neurocrine and paracrine messengers. Clin Gastroenterol
$1980 ; 3: 485-516$.

4 Stern L, Tenenhouse A, Yu EWT. Uptake, storage and secretion of 5-hydroxytryptamine and its amino acid precursor by dispersed rat pancreas acinar cells. $J$ Physiol 1983; 340: 555-67.

5 Thompson JH. Serotonin and the alimentary tract. Res Commun Chem Pathol Pharmacol 1971; 2: 687-781.

6 Falck B, Owman C. 5-hydroxytryptamine and related amines in endocrine cell systems. In: Garratini S, Shore PA, eds. Biological role of indolealkylamine derivatives. New York: Raven Press, 1968: 211-31.

7 Scheele GA, Palade GE. Studies on the guinea pig pancreas. Parallel discharge of exocrine enzyme activities. J Biol Chem 1975; 250: 2660-70.

8 Arnold $R$, von Hülst $M$, Neuhoff $C$, Schwarting $H$, Becker HD, Creutzfeldt W. Antral gastrin-producing Gcells and somatostatin producing D-cells in different states of gastric acid secretion. Gut 1982; 23: 285-91.

9 Richter G. Stöckmann F, Conlon JM, Creutzfeldt W. Serotonin release into blood following food and pentagastrin: Studies in healthy subjects and in patients with metastatic carcinoid tumors. Gastroenterology 1986; 91: 612-18.

10 Inokeuchi H, Kawai K, Takeuchi Y, Sano Y. Immunohistological demonstration of EC cells in rat gastrointestinal tract. Histochemistry 1982; 74: 453-6.

11 Inokeuchi H, Kawai K, Takeuchi Y, Sano Y. Immunohistochemical study on the morphology of enterochromaffin cells in the human fundic mucosa. Cell Tissue Res 1984; 235: 703-5.

12 Gylfe E, Hellmann B, Sehlin J, Taljidal IB. Amino acid conversion into 5-hydroxytryptamine in pancreatic $\beta$ cells. Endocrinology 1973; 93: 932-7. 